\title{
Present status of renal replacement therapy in Asian countries as of 2017: Vietnam, Myanmar, and Cambodia
}

\author{
Toru Hyodo ${ }^{1 *}$, Masafumi Fukagawa', Nobuhito Hirawa', Yoshitaka Isaka', Hidetomo Nakamoto², Pham Van Bui ${ }^{3,4}$,
} Khin Thida Thwin ${ }^{5}$ and Chanseila Hy ${ }^{6}$

\begin{abstract}
Since 2015, the Committee of International Communication on Academic Research of the Japanese Society for Dialysis Therapy has held its Asian symposium during the society's Annual Congress to discuss the present status of and demand for dialysis therapy in Asian countries. The aim of the symposium is to identify needs and find ways to contribute in the area of dialysis therapy in these countries. Three manuscripts are presented here by participants at the 2017 Asian symposium from Vietnam, Myanmar, and Cambodia.

With economic development, hemodialysis (HD) therapy is now available worldwide. However, the cost of HD is very high compared with the average income in these three countries and, as of 2017, Cambodia and Myanmar have not yet established national health insurance systems. In Cambodia, patients must bear 100\% of the cost for dialysis. In Myanmar, the government covers the cost of HD (20 USD, 40\% of total cost) in public HD centers, but this service is still insufficient to meet current demand, with long waiting lists of up to 6 months at government HD centers. In contrast, in Vietnam, dialysis is almost completely covered by national health insurance. Dialyzers tend to be reused in all three countries. Continuous ambulatory peritoneal dialysis is available in Vietnam and Myanmar but not in Cambodia. Viable health insurance systems should be established as soon as possible in Cambodia and Myanmar, although this will ultimately depend on the countries' level of economic development.
\end{abstract}

Keywords: Committee of International Communication for Academic Research of the Japanese Society for Dialysis Therapy, Asian developing countries, Dialysis therapy, Economic development, Vietnam, Kidney transplantation, Chronic kidney disease, Peritoneal dialysis, Dialysis nurses, Dialysis doctors, Clinical engineers, Myanmar, Cambodia, Khmer Rouge-controlled state, Hemodialysis, National health insurance system

\section{Background}

Preface: relationship between the Committee of International Communication for Academic Research of the Japanese Society for Dialysis Therapy and Asian developing countries until 2017

Toru Hyodo, Masafumi Fukagawa, Nobuhito Hirawa, Yoshitaka Isaka, Hidetomo Nakamoto, Japan

\footnotetext{
* Correspondence: thyodomd@gmail.com

${ }^{1}$ The Committee of International Communication for Academic Research of the Japanese Society for Dialysis Therapy, Tokyo, Japan

Full list of author information is available at the end of the article
}

Recently, developing countries in Asia are showing marked economic development and rapid growth in terms of information and communications technology. These technologies allow physicians as well as the general public in these countries to learn about the latest treatments provided in developed countries as they occur. As a result, demand is rapidly growing for healthcare services of the same standard as those available in developed countries. People now know that diseases once deemed incurable in their home countries can now be treated with advanced methods in developed

(c) The Author(s). 2020 Open Access This article is licensed under a Creative Commons Attribution 4.0 International License, which permits use, sharing, adaptation, distribution and reproduction in any medium or format, as long as you give appropriate credit to the original author(s) and the source, provide a link to the Creative Commons licence, and indicate if changes were made. The images or other third party material in this article are included in the article's Creative Commons licence, unless indicated otherwise in a credit line to the material. If material is not included in the article's Creative Commons licence and your intended use is not permitted by statutory regulation or exceeds the permitted use, you will need to obtain permission directly from the copyright holder. To view a copy of this licence, visit http://creativecommons.org/licenses/by/4.0/ The Creative Commons Public Domain Dedication waiver (http://creativecommons.org/publicdomain/zero/1.0/) applies to the data made available in this article, unless otherwise stated in a credit line to the data. 
countries. Dialysis therapy is a typical example. Since 2015, the Committee of International Communication for Academic Research of the Japanese Society for Dialysis Therapy (JSDT) has held the first, second, and third Asian symposia at the society's Annual Congress to discuss the present status of and demand for dialysis therapy in Asian countries in order to identify how to contribute in the area of dialysis therapy in these countries. The first symposium in 2015 covered the current status in Myanmar, Vietnam, Thailand, China, and Japan; the second symposium in 2016 introduced issues in Cambodia, Laos, Bhutan, Mongolia, and Indonesia; and the third symposium in 2017 provided updates for Vietnam, Myanmar, and Cambodia.

We hope that this report from the 2017 Asian symposium on the status of dialysis therapy in the three countries will be helpful to developed countries in providing support activities to developing countries.

\section{History and status of dialysis development in Vietnam Pham Van Bui, Vietnam}

\section{The geography of Vietnam}

Vietnam is the easternmost country on the Southeast Asian Indochinese Peninsula. With an estimated 95.5 million inhabitants as of 2018, it is the 15th most populous country in the world. Vietnam shares its land borders with China to the north, and Laos and Cambodia to the west. It shares its maritime borders with Thailand through the Gulf of Thailand, and the Philippines, Indonesia, and Malaysia through the South China Sea. Its capital city is Hanoi, while its most populous city and commercial hub is Ho Chi Minh City, also known by its former name of Saigon [1, 2] (Fig. 1).

\section{The general aspect of CKD of Vietnam}

Based on preliminary studies, the incidence of chronic kidney disease (CKD) is about 120 per million population in Vietnam, and more than 90,000 patients are in need of dialysis. More alarmingly, up to 9000 incident cases are underdiagnosed and undertreated every year. In fact, by the end of 2016, only about 21,000 patients were being treated with maintenance hemodialysis (MHD), peritoneal dialysis (PD), or renal transplantation.

The most common causes of CKD are type 2 diabetes mellitus (T2DM), hypertension, tubulointerstitial nephritis, and infection or urological-related diseases. In fact, Vietnam is among the top 10 countries in the AsiaPacific region with the fastest rate of T2DM development. The majority of patients with kidney disease are managed in the fields of endocrinology, cardiology, and internal medicine, and they are referred to nephrologists only when the kidney disease has advanced to the endstage.

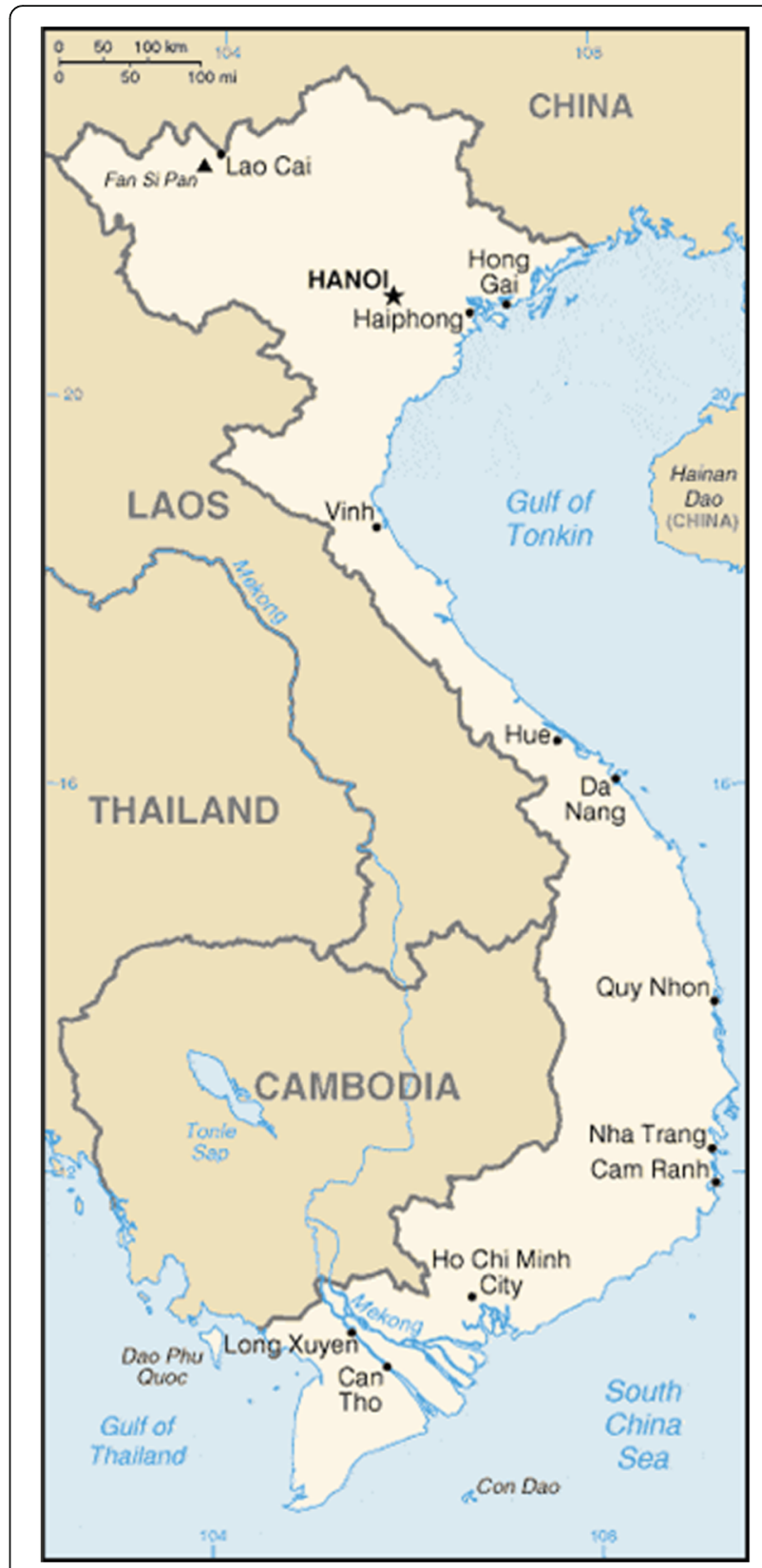

Fig. 1 The geography of Vietnam

\section{History of dialysis}

Hemodialysis (HD) was introduced in Vietnam very early, in 1968, in the Urology Department of the University Binh Dan Hospital. I worked in this department as a surgeon and was in charge of the Dialysis Unit for 16 years after graduating in 1980 from the Medical University in Saigon City (now Ho Chi Minh City). However, from its introduction until 1983, HD was used to treat acute renal failure only. Then, from 1983 to 1986, HD was used as MHD to treat 3 patients with end-stage renal disease (ESRD). Despite showing remarkable clinical and biological improvement after those first dialysis 
sessions, they survived for just a short time. During this period, there was only one machine in use, a Travenol Drake-Willock HD machine. It was a positive semirecirculating system with a tank containing $120 \mathrm{~L}$ of dialysate made by manually diluting $4 \mathrm{~L}$ of prepared concentrate dialysate from old stock left from the war in $116 \mathrm{~L}$ of tap water (there were no water treatment systems available at that time). The dialyzer was a coil type with a priming volume of more than $1 \mathrm{~L}$. In 1987, we started treating more ESRD patients using 12 simple, recirculating machines (Fig. 2) without any monitoring devices. These machines were assembled by a FrenchVietnamese. He had been on dialysis himself in France for more than 15 years, and he assembled the machines using spare parts from discarded machines in France in order to treat himself during his stay in Vietnam. When he left the country, he donated the machines to our hospital, so that we could continue treating others with ESRD. However, fewer than 60 ESRD patients were receiving MHD at that time because they had to bear the cost of all medical expenses, which was prohibitive considering the average income. Even though the equipment was simple, the survival rate was encouraging, with more than $80 \%$ of patients surviving for more than 5 years. This survival rate prompted the growth of chronic dialysis in Vietnam, and we started organizing dialysis training courses for physicians and nurses working in other hospitals.

In 1996, a new HD center with 10 Gambro AK-10 HD machines equipped with ultrafiltration control systems (Fig. 3) was established in Hospital Popular 115 with aid from a French non-governmental organization. I was appointed to Head of the center. Also in 1996, Vietnam's health insurance system was revised to cover $80 \%$ of the cost of dialysis treatment. These two developments, together with improvement of the Vietnamese economy, led to a steep rise in the number of patients on MHD.

\section{Hemodialysis}

So far, HD has been the preferred treatment, with about 17,500 patients on MHD; this remains far below the current need, however. Dialysis facilities are now available in most cities and provinces. In some big cities or provinces like Ho Chi Minh City, these facilities are also available in district hospitals (secondary hospitals). Although all centers run about 4 shifts per day, the patient load is overwhelming. The number of facilities has increased, mainly in the public sector, and the majority of machines are either rented or purchased on long-term installment payments. In fact, in many hospitals, the board of directors is hesitant to develop MHD facilities because of the huge monetary investment needed in infrastructure and receipt of only low fixed-price reimbursements from insurance, which are far lower than the actual costs of HD. Those facilities that do offer MHD employ various means to try to make up at least some of the loss. These include reusing the dialyzer many times (dialyzer reimbursement is allowed only once every 6 reuses), buying low-flux instead of high-flux dialyzers and blood lines made by non-accredited companies (with unknown quality and safety profiles), prescribing non-HD generic/biosimilar medicine, and using unfractionated heparin for anticoagulant therapy.

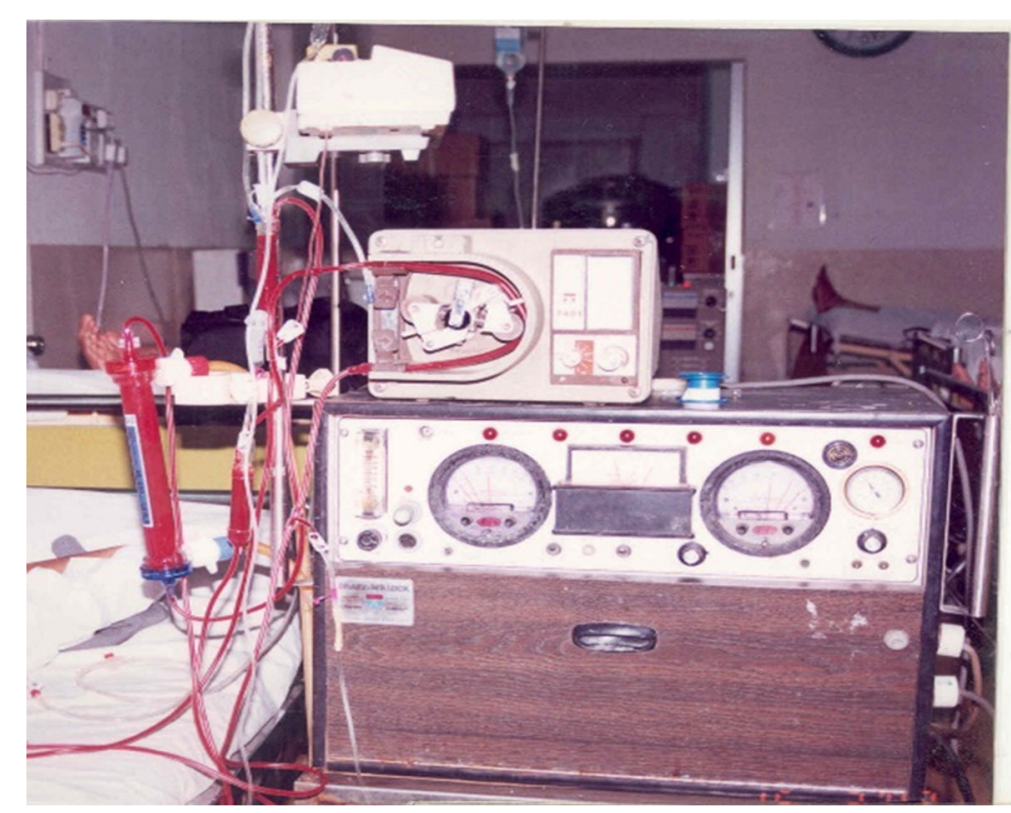

Fig. 2 Dialysis machine made by assembling spare parts from machines discarded in France 


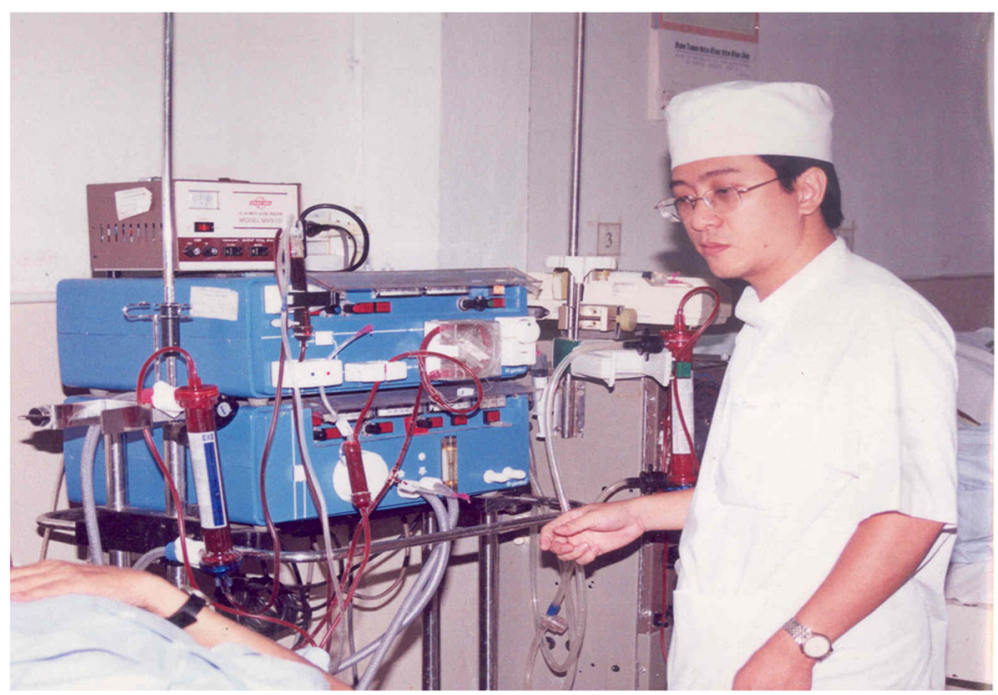

Fig. 3 A Gambro AK 10 machine donated by a French non-governmental organization

Conventional HD is more common in most practices, while online HDF is available in only a few facilities because costs are only partially reimbursed by insurance. Moreover, the indications and effectiveness remain controversial and unclear. Most HD facilities use locally made bicarbonate dialysate, and all use water treatment systems with softeners and reverse osmosis devices; however, the water quality is questionable due to lack of regular maintenance. The dialysis machines are all new and modern with venous pressure, blood and dialysate flow, conductivity, and temperature monitors, as well as an ultrafiltration controller, air detector, and other basic components.

Unfortunately, most Vietnamese patients on MHD have poor quality of life due to various problems:

1. Delayed initiation of dialysis: almost all patients have severe comorbidities at the time of dialysis initiation or develop dialysis-related complications such as left ventricular hypertrophy, heart failure, coronary artery disease, uncontrolled arterial hypertension, anemia, malnutrition, and bone mineral disease.

2. Negative thinking of patients: the majority feel incapacitated or hopeless and consider HD as just a means for day-to-day survival.

3. Poor compliance with medical advice: for example, patients have poor adherence to treatment, intentionally skip scheduled dialysis sessions, and gain excessive interdialytic weight due to unrestricted diets.

4. Poor quality of dialysis: including low-flux dialyzers, dialyzer reuse, poor quality water, unqualified healthcare providers, and dialysis inadequacy.

\section{Educational program}

An important problem in dialysis is healthcare provider qualification. Most physicians, nurses, and other healthcare providers working in dialysis are considered specialists if they work in nephrology and/or dialysis departments for a long time even if they have no academic training in these fields. For the past 2 years, we have organized 3 courses and 3 congresses for nurses and physicians working in these fields across Vietnam; these programs are accredited by the Ministry of Health. The Nguyen Tri Phuong University Hospital was approved as a continuing medical education (CME) establishment for Nephrology-Dialysis, and the Ho Chi Minh City Society for Dialysis Therapies was also established (of which I am president). Although each CME course lasts just 3 months and each congress lasts 2 days, we provide attendees with basic knowledge in nephrology-dialysis so that they can obtain certification and the license to practice. I would like to take this opportunity to express my gratitude to our Japanese colleagues from JSDT and Tanaka Urology Clinic for their excellent lectures and their valuable contributions to the success of these courses and congresses. Last but not least, since August 2016, a non-profit hi-tech dialysis center supported by Tanaka Urology Clinic of Japan has been introduced in Nguyen Tri Phuong Hospital. In this exceptional center, all dialyzers are high-flux, branded, and single-used, and the machines are of newer generation with an endotoxin filter resulting in water of excellent quality being supplied for dialysis (Fig. 4). Although patients have to pay extra fees, after reimbursement they all appear very satisfied and feel much better with $\mathrm{Kt} / \mathrm{V} \geq 1.4$. Hopefully, more centers in Vietnam will be developed based on this model to improve the quality of life of dialyzed patients. 

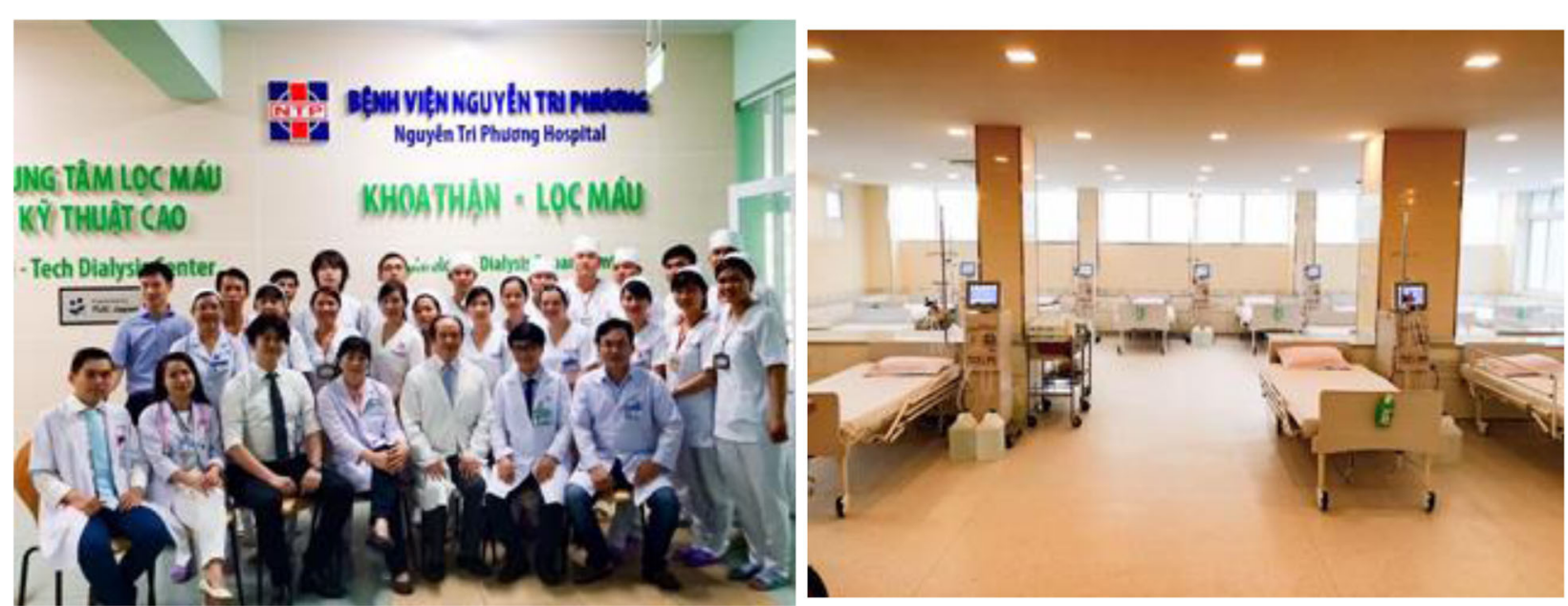

Fig. 4 A non-profit hi-tech dialysis center introduced in Nguyen Tri Phuong Hospital

\section{Peritoneal dialysis}

I have been pioneering the development of PD in Vietnam since 1998, and only continuous ambulatory peritoneal dialysis (CAPD) is currently available. Unfortunately, compared with HD, CAPD is still not well developed, with fewer than 2000 patients treated in almost 20 years. The most common reason for CAPD underuse is patients' preference; many fear infection and prefer access via the wrist than via the abdomen. In addition, in many cases, the home setting is not suitable for PD, so the PD complication-related drop rate is quite high.

\section{Kidney transplantation}

The first kidney transplantation with a kidney from a living donor was performed in 1992 in a military hospital in north Vietnam with the support of a Taiwanese professor. Since then, approximately more than 3500 patients have received transplants mainly from living donors in addition to a few hundred done in China many years ago and being followed up in Vietnam. The 1-year survival is nearly $97 \%$. For immunosuppressive treatment, we use basiliximab, tacrolimus, cyclosporin A, azathioprine, mycophenolate mofetil, and corticosteroids. Although it is the best of the renal replacement therapy modalities available, the main factors contributing to the limited number of transplantations are a shortage of donor organs, the high cost of treatment, and the only $50 \%$ reimbursement for immunosuppressive drugs.

\section{Health insurance system}

Compared with many other health insurance systems, Vietnam's is quite good. Public insurance is the most common, and all workers and employees have insurance provided by their employers. For the poor and designated past revolutionaries, the government reserves social funds for insurance. A notable characteristic of public health insurance in Vietnam, which is very humanitarian, is that patients can obtain insurance once they start dialysis. This policy is also extended to cover other chronic diseases such as cancer and diabetes.

So far, about $80 \%$ of the population have health insurance, and with a set target of $100 \%$ by the year 2020 , the Vietnamese government has launched a policy called "Family package" to encourage everyone to obtain insurance. All family members must obtain insurance but at a discounted rate calculated according to the number of family members; for example, for a family of 5 , the price of the first member would be about 30 USD per year; the second, 20\% less than 30 USD; the third, 30\% less, and so the price for the whole family of 5 would be about just 100 USD per year. Also, the insured have the right to choose their preferred hospital.

Reimbursement for dialysis ranges from 80 to $100 \%$ and that for PD is determined based on the number of dialysate bags used; reimbursement for HD is fixed at about 22-25 USD per session depending on the hospital ranking. Some, but not all, public hospitals require patients on dialysis to pay extra fees, whereas private hospitals always charge an additional fee of about 50 USD per session after reimbursement. Most dialyzed patients are underprivileged, but fortunately more than $95 \%$ are covered by insurance. Besides, costs for non-HD medicines such as erythropoietin-stimulating agents or antihypertensive drugs are reimbursed separately. Although reimbursement for HD costs is rather low, the availability of insurance has nonetheless helped underprivileged patients to afford dialysis and extend their survival, as well as contributed greatly to the development of renal replacement therapies in Vietnam. 
HD facilities in Myanmar in 2017

Khin Thida Thwin, Myanmar

\section{Introduction}

Myanmar is a country in Southeast Asia. Myanmar is bordered by Bangladesh and India to its northwest, China to its northeast, Laos and Thailand to its east and southeast, and the Andaman Sea and the Bay of Bengal to its south and southwest. With a size of $676,578 \mathrm{~km}^{2}\left(261,228 \mathrm{mi}^{2}\right)$, Myanmar is the largest of the Mainland Southeast Asian states by area. As of 2017, the population is about 54 million. Its capital city is Naypyidaw, and its largest city is Yangon (Rangoon). Myanmar has been a member of the Association of Southeast Asian Nations (ASEAN) since 1997 [3, 4] (Fig. 5). The prevalence of CKD has risen from 1786 cases per million population in 2005 to 3855 in 2012 (according to hospital and patient data from the Ministry of Health $[\mathrm{MOH}])$.

\section{Health care system}

The health care system provides universal health coverage to the public in government hospitals. Within the Ministry of Health and Sports (MOHS), there are specialist hospitals, teaching hospitals of medical universities, state and divisional hospitals, district hospitals, township hospitals, station health centers, and rural health centers. A total of 5 nephrology departments offer specialized services to the public and for undergraduate and postgraduate medical training in 4 medical universities.

\section{Types of dialysis}

Hemodialysis (HD) (Fig. 6a), hemodiafiltration (HDF) (Fig. 6b), and CAPD are used in ESRD. HD, HDF, sustained low-efficiency dialysis (SLED) (Fig. 6b), and acute PD are used in acute kidney injury.

\section{History of dialysis}

HD was first introduced using a coil system dialyzer at the Defense Services General Hospital in 1970. The $\mathrm{MOH}$ established HD using the automated B Braun machine at Yangon General Hospital in 1995. Private HD centers were established from the following year. Home HD facilities are still few.

There are 52 HD centers around Myanmar; 25 of which are government run and 27 of which are privately run (Fig. 7). Together, they offer $328 \mathrm{HD}$ machines and provide services to 1841 ESRD patients. In all HD centers, $43 \%$ of machines used are the Nipro system and others are the Fresenius, Nikkiso, B Braun, and Gambro systems.

In 2017, the number of patients undergoing dialysis therapy was 1841 receiving $\mathrm{HD}, 70$ receiving $\mathrm{HDF}$, and 20 on CAPD.

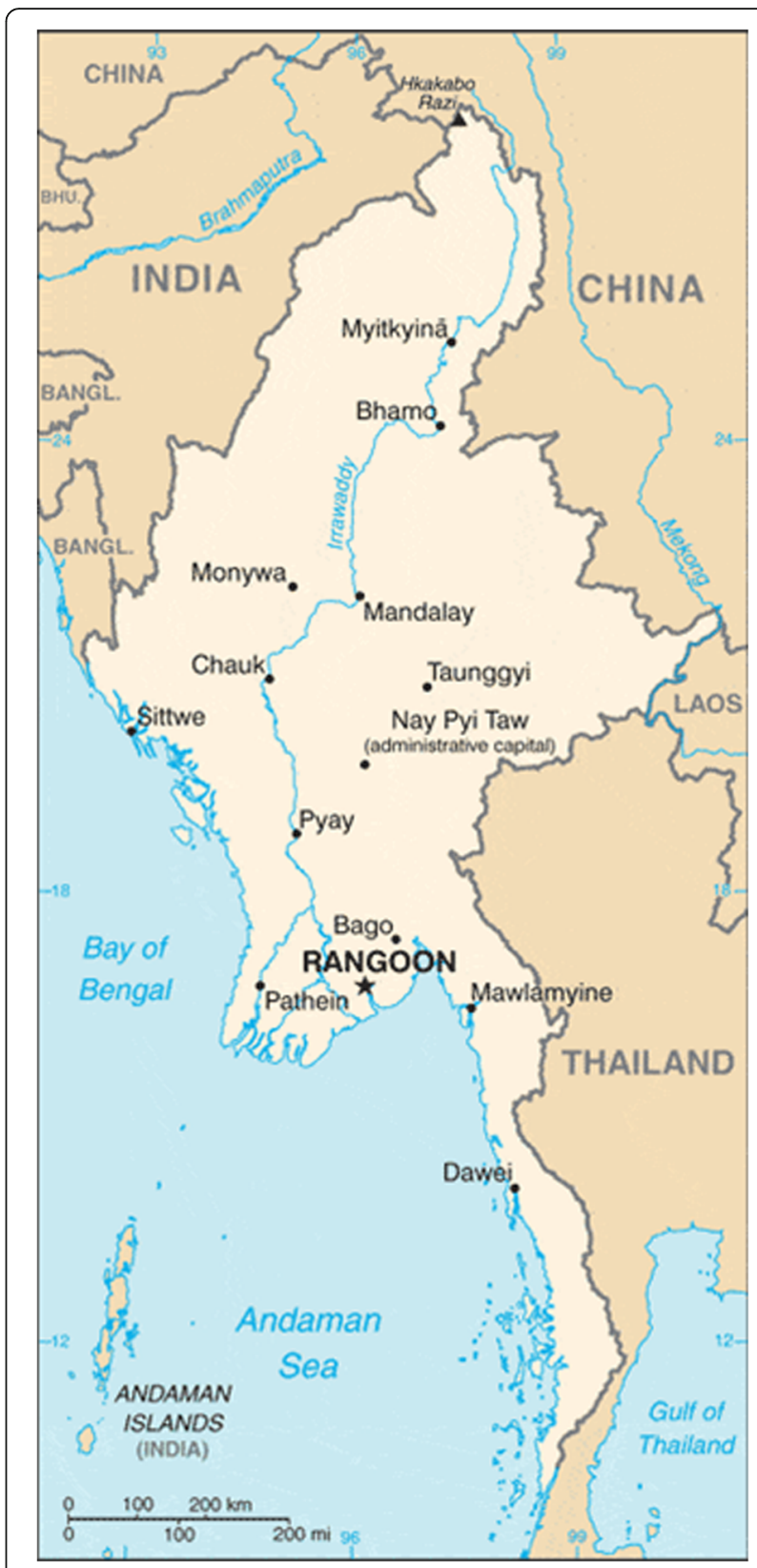

Fig. 5 The geography of Myanmar

\section{Causes of chronic kidney disease}

Diabetes mellitus is the main cause of CKD and ESRD (49\%), and other causes are hypertension (43\%) and chronic glomerulonephritis (8\%).

\section{Hemodialysis practice}

The HD frequency is 2 times per week for the majority of patients, and some have sessions 3 times per week. The duration for all types is $4 \mathrm{~h}$ per session, at a blood flow rate of $250 \mathrm{~mL} / \mathrm{min}$ and dialysate flow rate of 500 $\mathrm{mL} / \mathrm{min}$. 


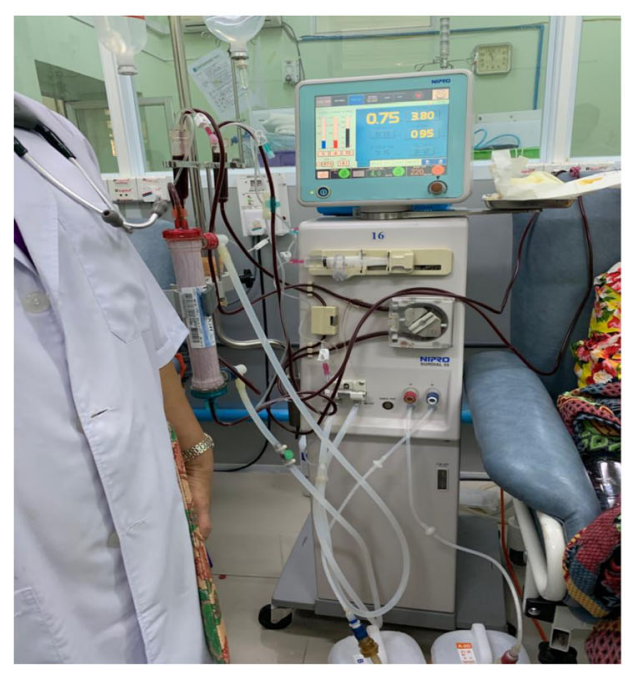

a

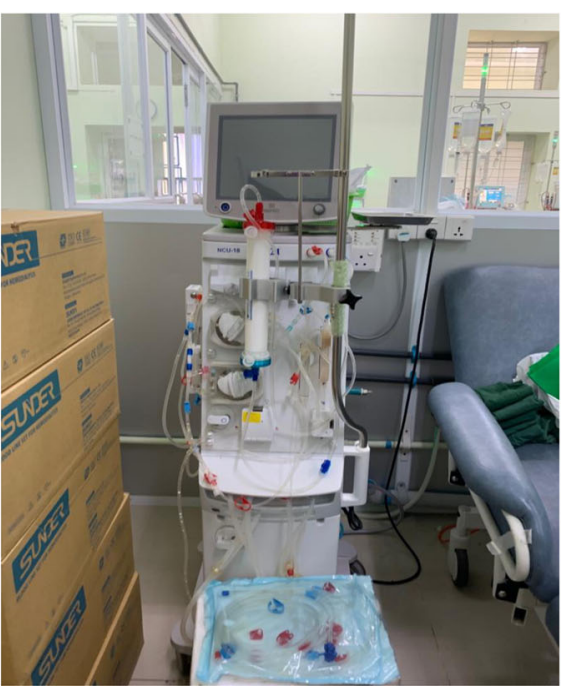

$\mathrm{b}$

Fig. 6 a The dialysis console. b The on-line HDF console which can perform the ordinary on-line HDF and SLED

Dialysate and reverse osmosis water are screened for infection by measuring endotoxin levels every 6 months, as well as bacterial count and chemical analysis every 3 months. Bleaching for all HD machines is done once a week.

\section{Health financing}

The cost of HD services is shared in some government centers and is 20 USD paid by the government, but the cost is 50 USD in private centers. There are some subsidized centers and a few charity centers, but the services provided are insufficient to meet the demand, so there are long waiting lists of up to 6 months in government HD centers.

For CAPD, the monthly cost is 300 USD for a 2-L bag at 3 exchanges per day. Notably, CAPD can also reduce the cost of transportation to HD centers. For HDF, the cost is 100 USD per session.

For other medications like erythropoietin, antihypertensives, and oral and parenteral iron, the costs are covered by the MOHS budget for inpatients and chronic HD patients at government hospitals.

As of this writing, Myanmar has no national health insurance system.

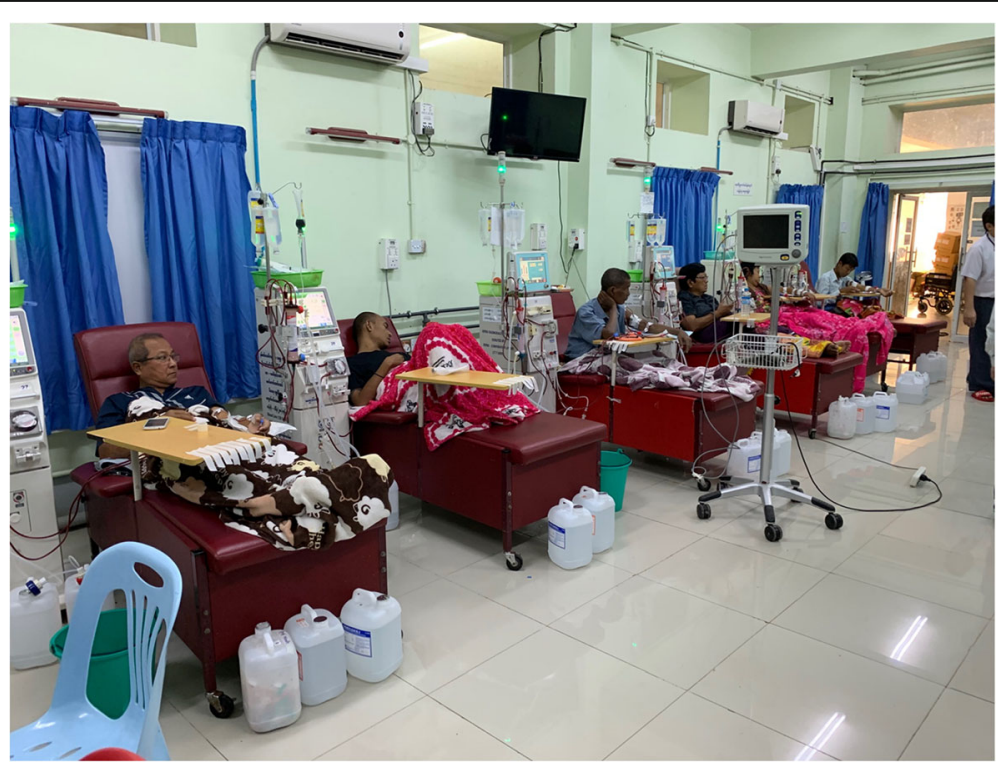

Fig. 7 A scene of the Dialysis Center of Yangon Specialty Hospital 


\section{Human resources training}

Dialysis nurse training has been carried out locally by experienced trainers in a 2-month training course. The aim is to establish new government HD centers in district areas. Training courses have been run 4 times a year in the nephrology departments at medical universities since 2015.

For CME and Continuing Professional Development for nursing staff, monthly CME meetings have been held at local hospitals, and nurses have been sent abroad to attend short international training courses, meetings, and conferences.

However, Myanmar has no clinical engineer support for dialysis, so all centers request backup engineer support services from the company of purchase. Thus, there is an urgent need for the MOHS to establish faculties of clinical engineering in universities to develop clinical engineers.

\section{Nephrology societies}

The Myanmar Nephrology Society was established in 2001 and was later combined with the Myanmar Urology Society to form the Myanmar Nephro-Uro Society. There are currently 60 faculty members, and the first National Conference was held in 2013. The conference is held on alternate years and so the third Conference was in 2017.

The Myanmar Nephro-Uro Society has hosted World Kidney Day public events since 2009 with the same aims and objectives of the International Society of Nephrology World Kidney Day team.

\section{Conclusion}

Dialysis is the most prevalent renal replacement therapy in Myanmar. However, it is insufficient to meet the needs of all ESRD patients. There is a pressing need for government reimbursement and national health insurance to provide universal health coverage. Also, we need a national policy on living and deceased donor kidney transplant programs and PD for ESRD patients, especially those in remote areas. The MOHS will therefore need support from non-governmental international organizations like the National Kidney Foundation to encourage the establishment of similar organizations. There is also a need to set up a nephrology diploma course for nurses, technical training for clinical engineers, and training for dieticians and pharmacists in the future.

\section{History and status of dialysis in Cambodia and establishment of the Cambodia Association of Nephrology \\ Chanseila Hy, Cambodia}

\section{Preface about renal replacement therapy in Cambodia}

The status of renal replacement therapy in Cambodia had been described in the former report in this journal [5].

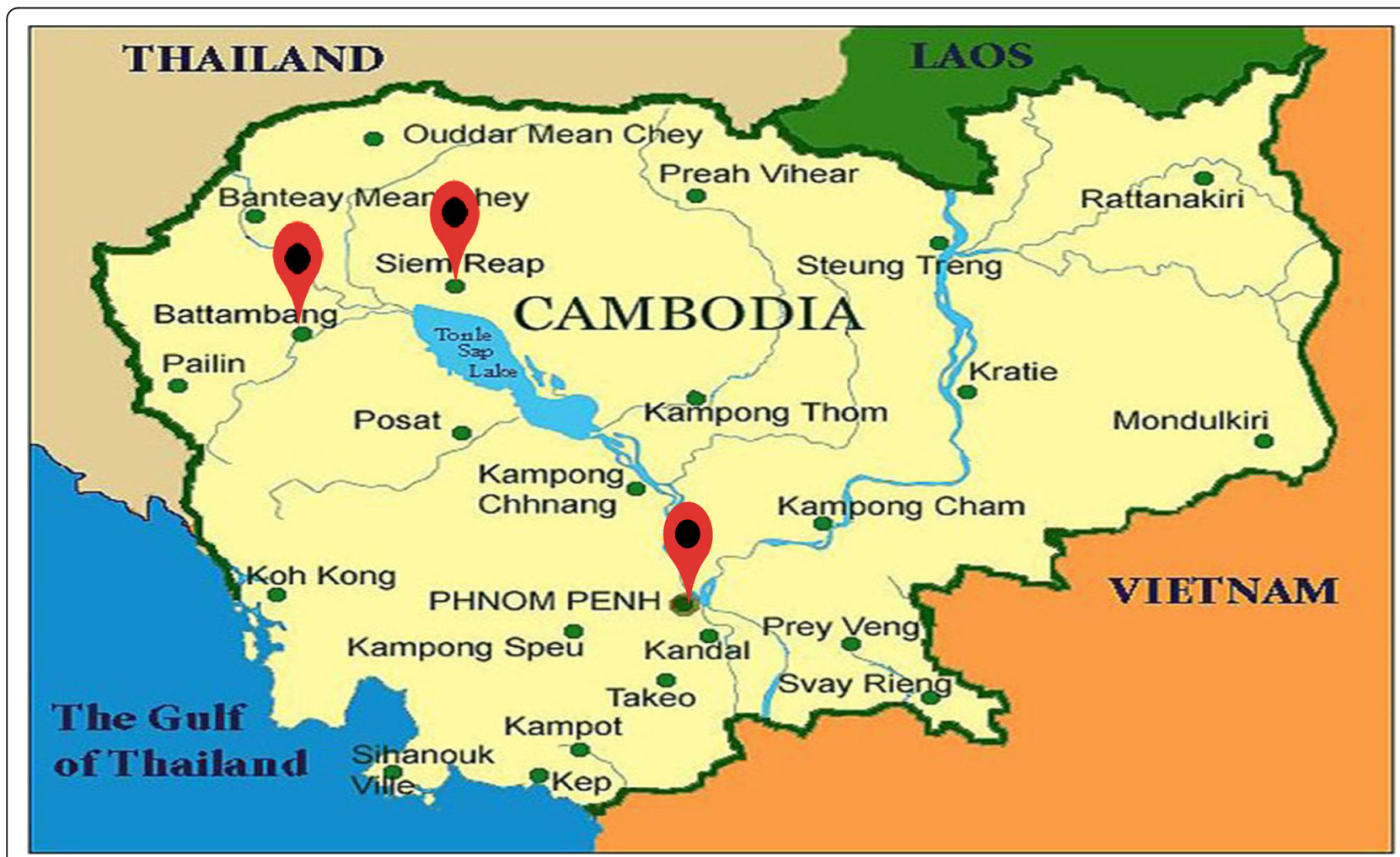

Fig. 8 The geography of Cambodia. The dialysis centers are located in the red pointed 3 cities (Phnom Penh, Siem Reap, and Battambang) 


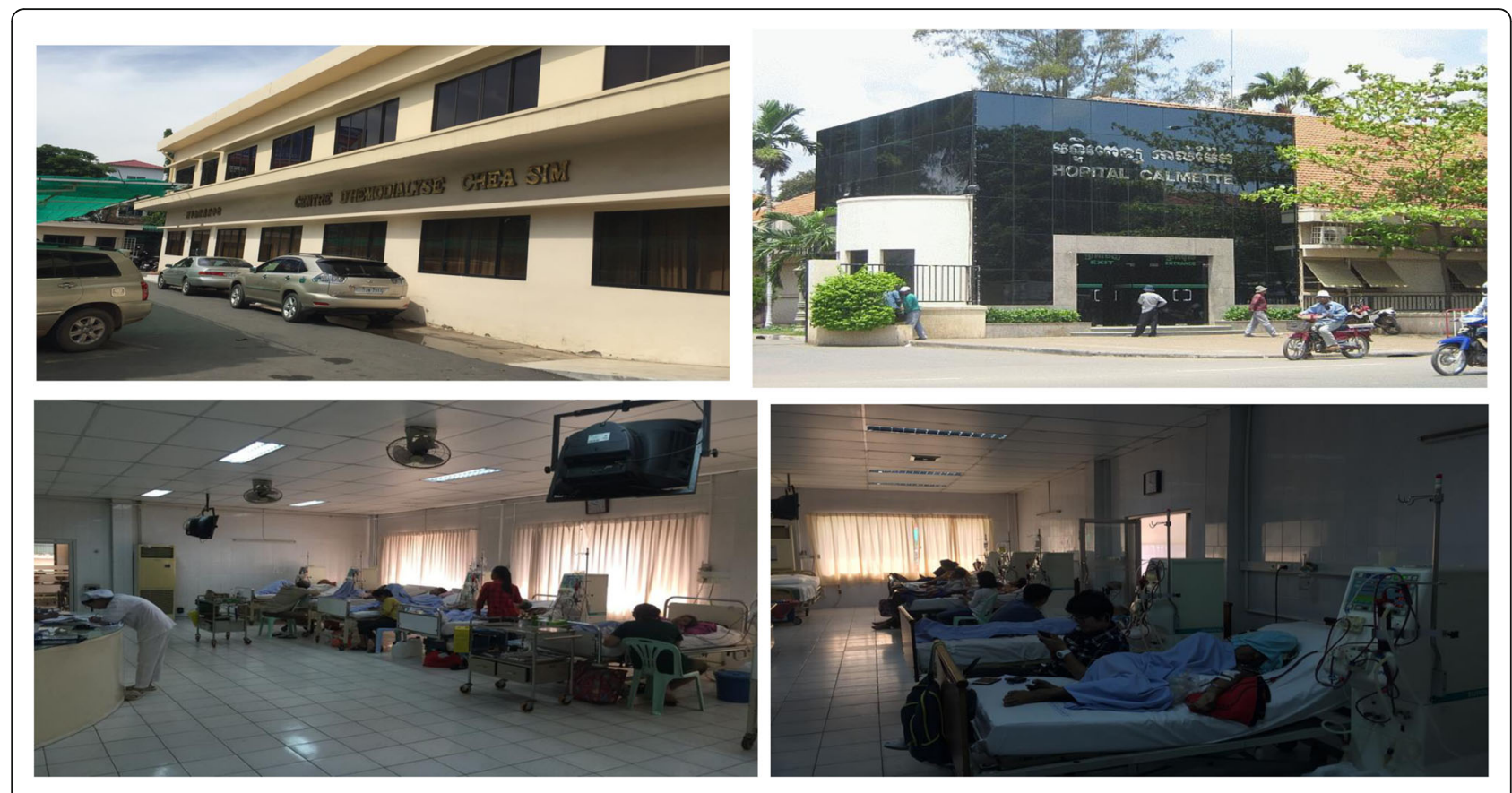

Fig. 9 Chea Sim Hemodialysis Center at Calmette Hospital in Phnom Penh

That status has been improved after the establishment of the Cambodian Association of Nephrology in 2016. I would like to stress it in this manuscript.

\section{Geography of Cambodia}

Cambodia is a country located in the southern portion of the Indochina peninsula in Southeast Asia. It is 181, $035 \mathrm{~km}^{2}\left(69,898 \mathrm{mi}^{2}\right)$ in area, bordered by Thailand to the northwest, Laos to the northeast, Vietnam to the east and the Gulf of Thailand to the southwest. It covers a total area of $181,035 \mathrm{~km}^{2}$, and its capital city is Phnom Penh. The country has a population of approximately 15 million. There are two main seasons in Cambodia: a rainy season and a dry season. Ninety percent of Cambodians are Buddhists $[6,7]$ (Fig. 8).

\section{History of hemodialysis in Cambodia}

Following the tragedy of the genocidal Khmer Rouge regime and a dozen years of civil war, Cambodia has suffered massive destruction in so many ways, the healthcare system included. During the 3 years of genocide inflicted under the Pol Pot regime (1975-1979), most educated people were killed, and all hospitals were closed. From 1979, with a change of regime, the Cambodian government started to rebuild the country scratch. The country's development was stalled because the civil war continued until 1998. Fortunately, from 1979 onward, many public hospitals were reopened, though we had to confront numerous obstacles such as lack of equipment and human resources.
In 1997, the first HD center, the Chea Sim center, was opened in Phnom Penh at Calmette Hospital. At that time, there were only 4 machines that served approximately 10 patients. As of 2017, there were 26 machines in total, serving around 200 patients monthly (Fig. 9). In 2007, 2 more dialysis centers were set up in Phnom Penh, at Preah Ketmealea Hospital and at the Health Science Institute Hospital. Now there are 7 dialysis centers, including private centers, in Phnom Penh. Since 2015, dialysis therapy has been available in Battambong and Siem Reap provinces. The total number of dialysis patients is estimated to be around 600 nationwide, and we have in total about 150 console machines in public hospitals and private HD centers (Table 1, Fig. 8). Diabetes mellitus is the leading cause of ESRD in Cambodia. Hemodiafiltration is not yet available.

Table 1 Hemodialysis centers in Cambodia in 2017

\begin{tabular}{lll}
\hline $\begin{array}{l}\text { Public } \\
\text { center }\end{array}$ & $\begin{array}{l}\text { Phnom } \\
\text { Penh }\end{array}$ & Calmette Hospital (Civil) \\
& & Health Science Institute Hospital (Military) \\
& & Preah Ketmealea Hospital (Military) \\
& & Preah Kossamak Hospital (Civil) \\
Private & Piem Reap & Siem Reap Referral Hospital \\
& Penh & Cambodia-Japan Friendship Blood Purification \\
& & Center of Sen Sok International University \\
& Hospital \\
& La Sante Clinic \\
& Japan Life Clinic \\
& Battambang & Yi Kourk Clinic \\
\hline
\end{tabular}




\section{Maintenance of hemodialysis systems}

The HD machine maintenance system in our country is similar among dialysis centers (Figs. 10 and 11). Normally, an engineer from the dialysis machine company comes to do regular thorough machine checkup and maintenance, and technicians from the company carry out maintenance every month. The overall check-up and clean-up are done as follows.

- Check control panel

- Test function of machines: pump, drain valve, water refill valve, drain ball valve, use ball valve, flush out in clean mode, and drain out in clean mode.

- Check function of machines: clean mode, disinfect mode, spray nozzle rod, and clean float sensor.

- Check bacterial and endotoxin level of dialysate and reversal osmosis water at the console site every 3 months.

- Sterilize the console and the water line from the tank every month.

\section{Peritoneal dialysis}

Recently, we introduced CAPD (Fig. 12). We have trained nephrologists for PD, specialized nurses to provide explanations and care to PD patients, and urologists who can implant a peritoneal catheter. However, most patients prefer not to receive CAPD because of the complicated process involved and requirement for high-level knowledge. The few patients that do choose CAPD face problems with hygiene control and with the daily dialysate input and output process. CAPD is not only more expensive than HD, it is also very hard to find places or pharmacies where patients can buy solutions and systems for CAPD in Cambodia. So, this method does not work well in Cambodia yet. A Japanese doctor at the Sen Sok International University Hospital CambodiaJapan Friendship Blood Purification Center invited a leading global PD company to introduce CAPD to Cambodia in 2010, but this was not deemed possible because Cambodia at the time did not have a mature CAPD market. This situation has not changed as of 2017.

\section{Financial burden}

ESRD has been a significant financial burden for patients and their families, yet it is a low priority in government healthcare policies. Therefore, the cost of renal replacement therapy remains a major problem in Cambodia. The average cost of HD is 50 USD per session excluding the costs of the dialyzer and blood line. This is why patients ask to reuse their dialyzer at least 3 or 4 times before getting a new one. The cost of medicines such as antidiabetic and antihypertensive drugs and epoetin are also borne by the patient. Basically, currently in 2017, the cost for 1 patient to undergo HD 2 times per week is around 650-900 USD per month; household income is around just 150 USD per month. Treatment costs are

\section{5 microns Pump}

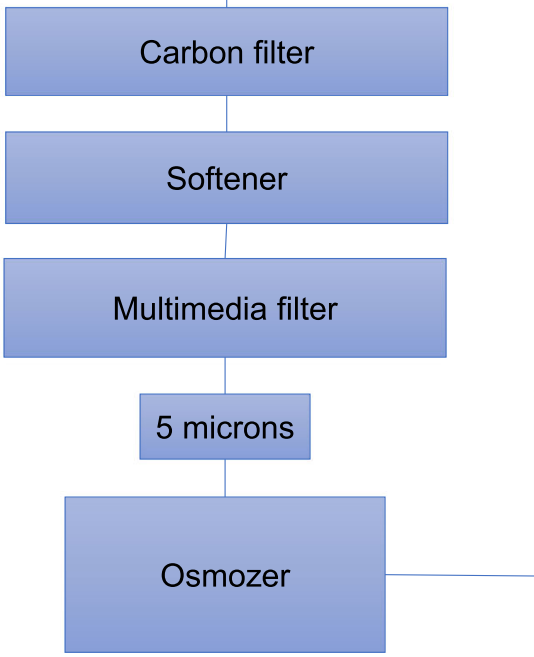

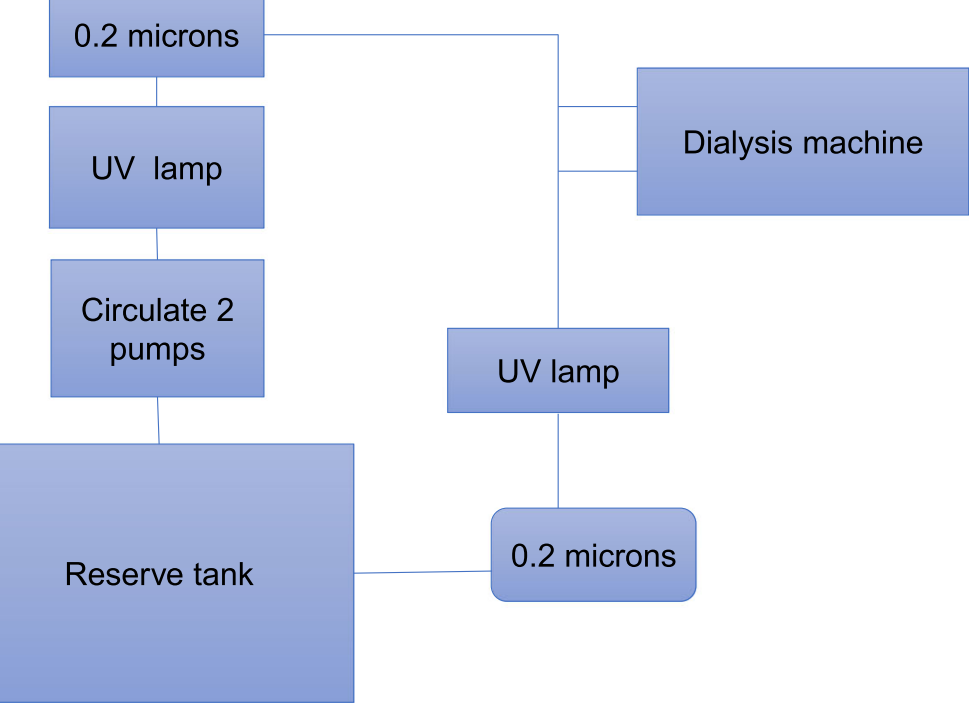

Fig. 10 Reverse osmosis water and its supply system at Chea Sim Hemodialysis Center 


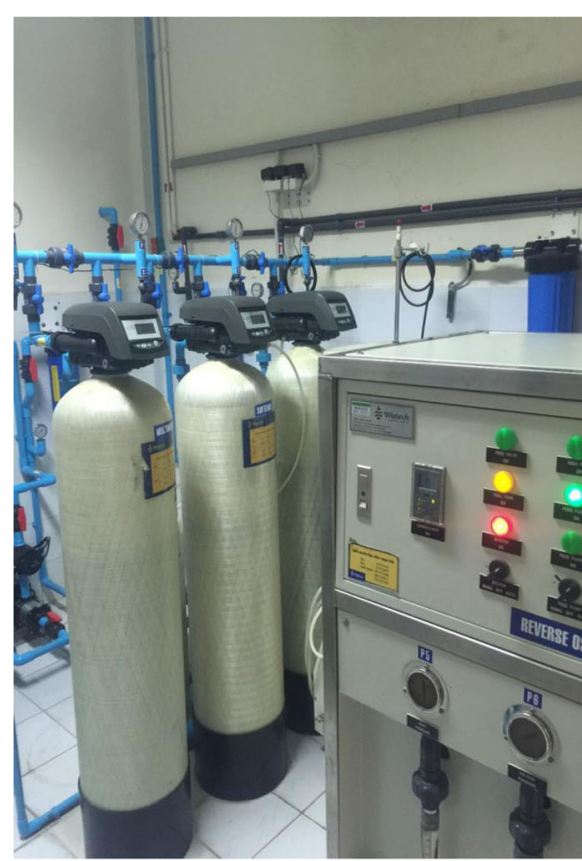

a

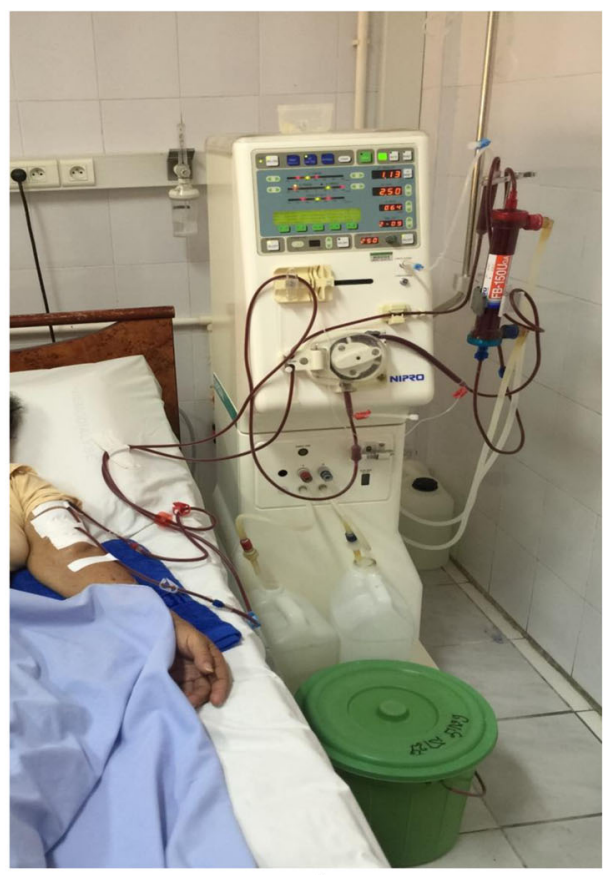

b

Fig. 11 The water purification and reverse osmosis system (a) and the dialysis console (b)

totally the patients' responsibility, with transportation and accommodation for patients from the provinces added on top (Fig. 13). Because of this heavy financial burden, some patients are forced to abandon their dialysis therapy and die, some patients decide to sell their property such as houses or land to pay for dialysis therapy, while others are left with a low quality of life caused by inadequate dialysis and anemia.

\section{Education}

$\mathrm{n}$ terms of local training for knowledge exchange, we have a collaborative effort with Thailand. We have sent doctors and nurses to train there. We also have exchange programs operating with developed countries such as France (exchange between universities) and Japan. An urgent need is for specialist dietitians because there are none in Cambodia.

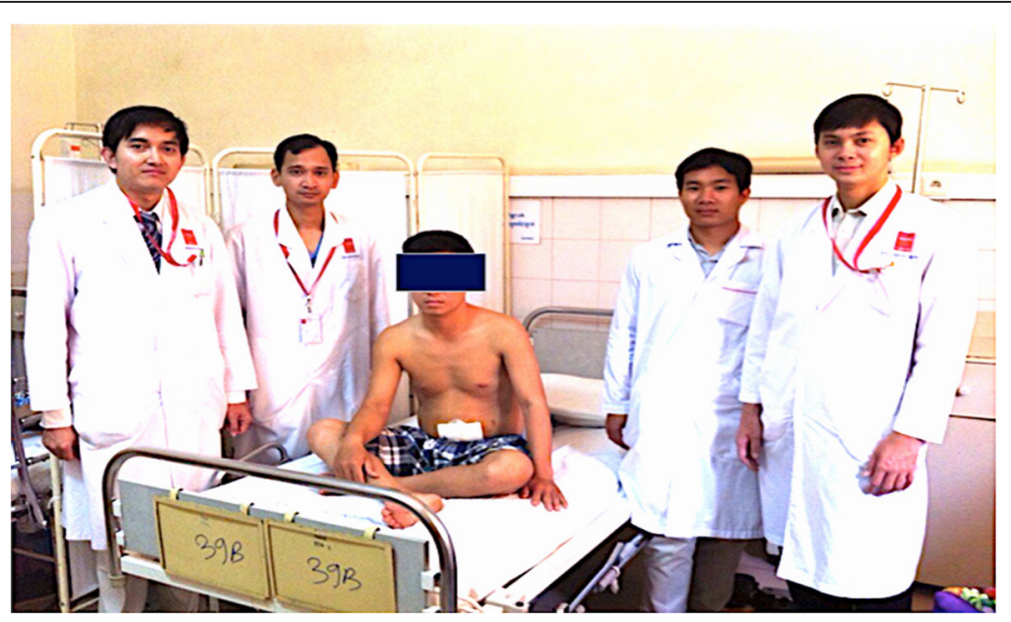

Figure 12 The first patient receiving peritoneal dialysis in Cambodia 

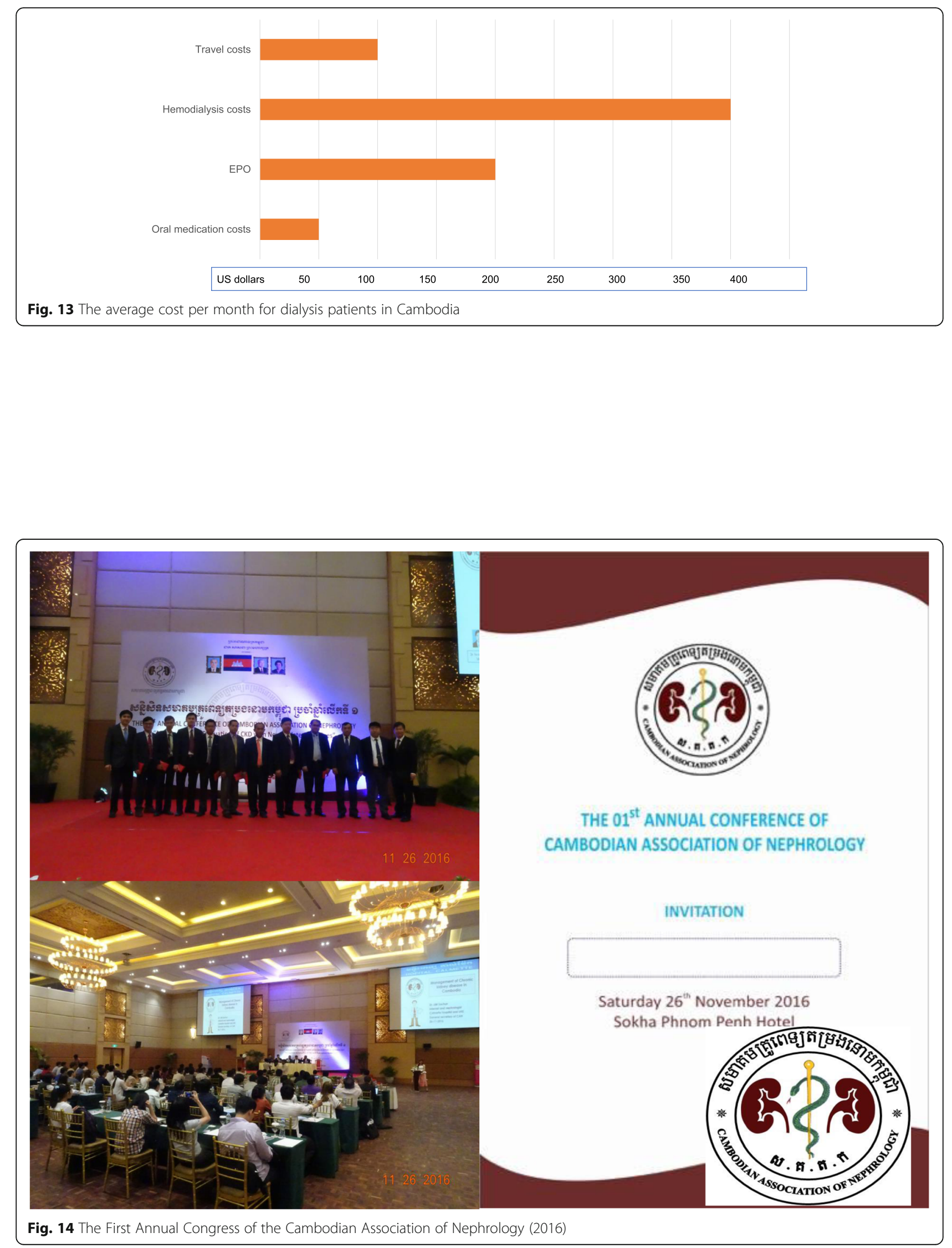


\section{Cambodian Association of Nephrology}

With the growing demand for dialysis services due to an increasing number of ESRD patients, there are $9 \mathrm{HD}$ centers and around $600 \mathrm{HD}$ patients nationwide. Thus, the Cambodian Association of Nephrology (CAN) was established in 2016 as an umbrella association for all nephrologists, nurses, and doctors who work in the field of nephrology and HD (Fig. 14).

\section{Goals of the Cambodian Association of Nephrology}

- To provide better care for patients with kidney disease and on dialysis by improving the knowledge of doctors and nurses who work in nephrology and dialysis. Accordingly, a meeting has been held every year since CAN was established.

- To spread knowledge about ESRD and dialysis, in order to address the issue of limited knowledge of
CKD among doctors, especially those in rural areas, we plan to create a program to educate all doctors from across the country, to increase understanding of nephrology and to identify the warning signs of these diseases.

- To find solutions to lower the cost of dialysis because around $80 \%$ of all patients can barely afford the cost of $\mathrm{HD}$ and the required medication

- To identify and establish more exchange programs in developed countries to improve our doctors' knowledge

\section{Recent activities of the Cambodian Association of Nephrology}

- CAN has held an annual meeting every year since 2016. The principal theme for each meeting is

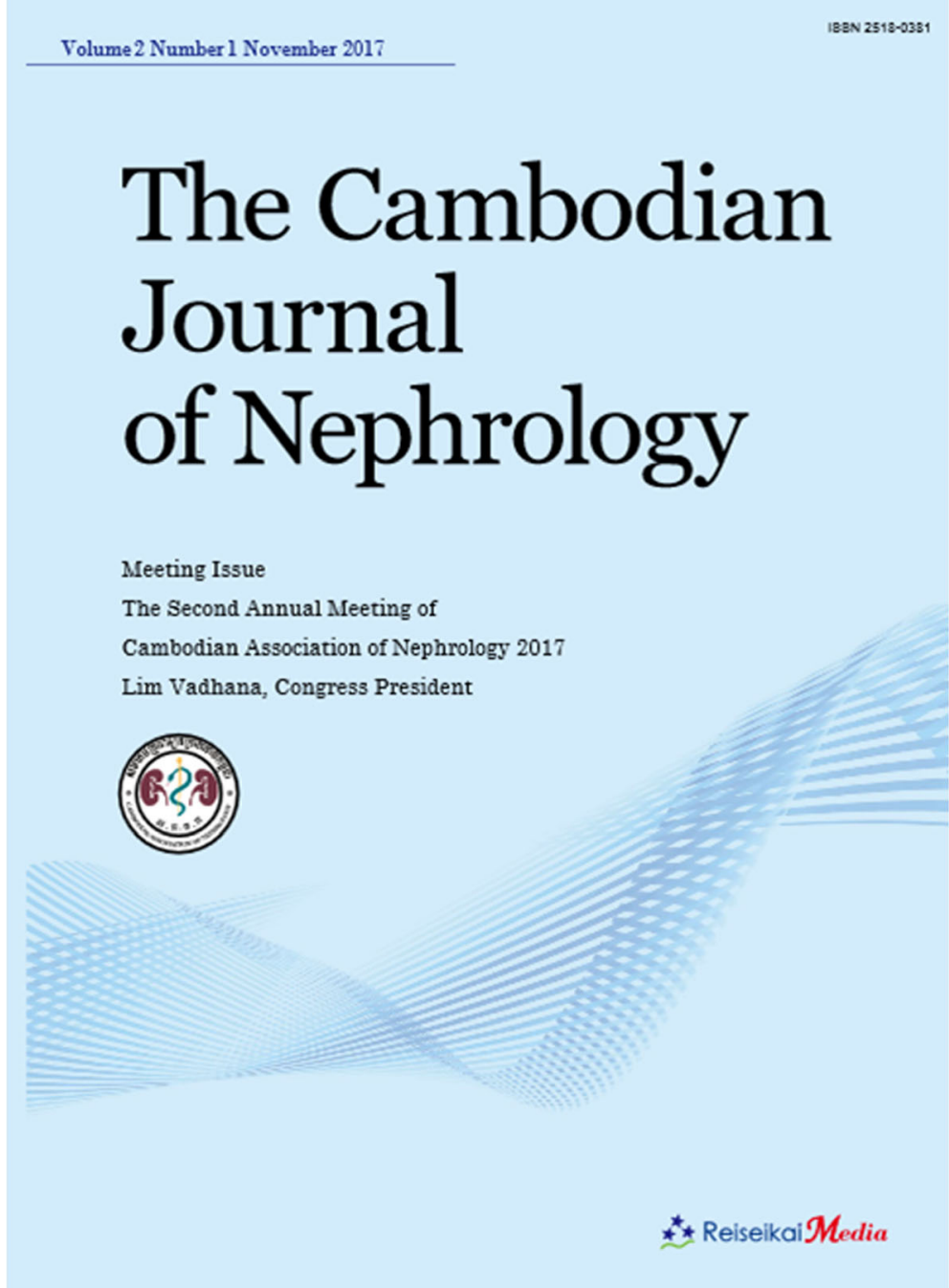

Fig. 15 The Cambodian Journal of Nephrology 
focused on the management of CKD and HD. We collaborate with a team from JSDT and there are usually 1 or 2 guest speakers from Japan in attendance. JSDT established the Human Resource Development Program Committee for Dialysis Specialists in Developing Countries and has been hosting several young doctors or medical students from the association and Cambodian medical colleges for short-term dialysis and CKD training courses (around 8 days) since 2016. There are also international speakers from other countries as well like Vietnam, Germany, and France. The goal of our annual meeting is to deliver new knowledge from experienced nephrologists to our personnel working in nephrology.

- CAN officially became affiliated with the International Society of Nephrology in June 2017.

- CAN has established and published our own official journal The Journal of Cambodian Nephrology (ISSN 2518-0381) in cooperation with Reiseikai Media (Cambodia) Co., Ltd. (Fig. 15) [8].

\section{Conclusion}

In the wake of genocide and civil war, Cambodia has put much effort into health sector reforms. Innovative modifications in dialysis practice are being made in our country to optimize outcomes. All of these efforts have led to the establishment of the health system that we have today. Even though there are still many challenges and obstacles in our path, progress has recently been made toward providing universal and sufficient nephrological care to all patients in need.

\section{Abbreviations}

JSDT: Japanese Society for Dialysis Therapy; CKD: Chronic kidney disease; MHD: Maintenance hemodialysis; PD: Peritoneal dialysis; T2DM: Type 2 diabetes mellitus; HD: Hemodialysis; ESRD: End-stage renal disease; CME: Continuing medical education; CAPD: Continuous ambulatory peritoneal dialysis; $\mathrm{MOH}$ : Ministry of Health; MOHS: Ministry of Health and Sports; IHD: Intermittent hemodialysis; HDF: Hemodiafiltration;

SLED: Sustained low efficiency dialysis; RO: Reverse osmosis

\section{Authors' contributions}

This report is a review article by the Committee of International Communication for Academic Research of JSDT. TH, MF, NH, and YI designed this report and are committee members. $\mathrm{HN}$ also designed this report and is president of JSDT. All other authors wrote their own reports. All authors read and approved the final manuscript.

\section{Funding}

Not applicable

\section{Availability of data and materials}

Not applicable

\section{Ethics approval and consent to participate}

Our manuscript does not report on or involve the use of any animal or human data or tissue.

\section{Consent for publication}

All reports do not contain personal data.

\section{Competing interests}

The authors declare that they have no competing interests.

\section{Author details}

${ }^{1}$ The Committee of International Communication for Academic Research of the Japanese Society for Dialysis Therapy, Tokyo, Japan. ${ }^{2}$ The Japanese Society for Dialysis Therapy, Tokyo, Japan. ${ }^{3}$ Department of Nephrology, Pham Ngoc Thach University of Medicine, Ho Chi Minh City, Vietnam. ${ }^{4}$ Department of Nephrology, Nguyen Tri Phuong University Hospital, Ho Chi Minh City, Vietnam. ${ }^{5}$ Department of Nephrology, University of Medicine (1), Yangon, Myanmar. ${ }^{6}$ Chea Sim Hemodialysis Center, Calmette Hospital, Phnom Penh, Cambodia.

Received: 28 December 2019 Accepted: 30 November 2020

Published online: 14 December 2020

References

1. Vietnam from Wikipedia, the free encyclopedia. https://en.wikipedia.org/ wiki/Vietnam.

2. Vietnam Google Map by driving directions. https://www. drivingdirectionsandmaps.com/vietnam-google-map/.

3. Myanmar from Wikipedia, the free encyclopedia. https://en.wikipedia.org/ wiki/Myanmar.

4. Myanmar Google Map by driving directions. https://www. drivingdirectionsandmaps.com/burma-google-map/.

5. Hyodo T, Fukagawa M, Hirawa N, Hayashi M, Nitta K, Chan S, et al. Present status of renal replacement therapy in Asian countries as of 2016: Cambodia, Laos, Mongolia, Bhutan, and Indonesia. Renal Replacement Therapy. 2019; 5(12) https://doi.org/10.1186/s41100-019-0206-y.

6. Cambodia from Wikipedia, the free encyclopedia. https://en.wikipedia.org/ wiki/Cambodia.

7. Cambodia Google Map. https://www.google.com/maps/place/Cambodia.

8. Website of the Cambodian Association of Nephrology. https://www. cambodia-nephrology.org/.

\section{Publisher's Note}

Springer Nature remains neutral with regard to jurisdictional claims in published maps and institutional affiliations.

\footnotetext{
Ready to submit your research? Choose BMC and benefit from:

- fast, convenient online submission

- thorough peer review by experienced researchers in your field

- rapid publication on acceptance

- support for research data, including large and complex data types

- gold Open Access which fosters wider collaboration and increased citations

- maximum visibility for your research: over $100 \mathrm{M}$ website views per year

At $\mathrm{BMC}$, research is always in progress.

Learn more biomedcentral.com/submission
} 